\title{
Alexithymia and Body Image in Saudi Arabian Females (University Students): Preliminary Data
}

\author{
Muwafak H. Al-Eithan ${ }^{a}$ Hend Alsulaiman $^{b}$ Iman M. Al-Eithan ${ }^{c}$ \\ ${ }^{a}$ Consultant Clinical Psychologist/Neuropsychologist, Private Practice, Riyadh, Saudi Arabia; ${ }^{b}$ Psychology \\ Department, King Abdelaziz University, Jeddah, Saudi Arabia; 'Psychology Department, Princes Noura University, \\ Riyadh, Saudi Arabia
}

\author{
Keywords \\ Eating · Female - Mood · Psychology - Toronto alexithymia \\ scale $\cdot$ Arabic
}

\begin{abstract}
Introduction: Alexithymia has been the focus of much recent research in relation to emotional regulation and eating problems amongst psychological disorders. It is dealing with difficulties in processing, expressing, and awareness of emotion. Body image has also been researched, especially amongst women, and its relation emotion. Objective: The aim of this exploratory study is to examine the presence of alexithymia and how this is related to body image amongst a group of female Saudi University students. Methods: 152 Arabic female students from a local University participated in the study. The Toronto Alexithymia Scale-20 (TAS-20 Arabic), the Therapeutic Alexithymia scale (PTA Scale) short scale, body image scale, and figure body image scale were all used in the study. Results: The results showed that there is significant correlation between TAS and body image scale. Further, results showed that body image scale is best predictor of alexithymia in regression analysis. Discussion: Alexithymia has not been studied in university students in KSA. We also
\end{abstract}

karger@karger.com www.karger.com/dmj

Karger $\stackrel{\text { ' }}{5}$

GOPEN ACCESS
(C) 2021 The Author(s)

Published by S. Karger AG, Basel

This is an Open Access article licensed under the Creative Commons Attribution-NonCommercial-4.0 International License (CC BY-NC) (http://www.karger.com/Services/OpenAccessLicense), applicable to the online version of the article only. Usage and distribution for commercial purposes requires written permission. explored its relationship to body image and found there is a significant correlation. Alexithymia is present and needs much research in this sample and beyond, in both clinical and non-clinical groups. Conclusion: This is the first study in an Arabic population to show the alexithymia is prevalent amongst this sample and it is significantly related to poor body image. Further studies are suggested to explore further psychological variables related to body image and eating problems, as well as on clinical samples is indicated.

(c) 2021 The Author(s)

Published by S. Karger AG, Basel

\section{Alexithymia}

Emotional regulations and difficulties may make the centre of psychopathology and positive psychology. Recent psychological literature has paid much attention to alexithymia in relation to many psychological disorders. Taylor and co-workers [1] demonstrated that Alexithymia (mainly considered as difficulties in expressing and identifying emotions) consists of 4 categories that illustrate facets of alexithymia: limitations in differentiating emotions from body sensations, limitations in identifying and expressing feelings, limited capacity for fantasy, 
and no abstract thinking with little capacity for selfawareness or introspection [1]. It has been proposed that alexithymia is related to experiences of trauma. Furthermore, features of alexithymia (i.e., difficulties with emotions and expressing them) help an individual's need to have better control after certain traumas [2]. There has been an association between alexithymia and emotional problems, compared to others with no alexithymia patients have been shown to have much higher levels of emotional distress than non-alexithymia $[1,3]$. Recent research suggests that different degrees of alexithymia severity reflect differences in the structure of the cognitive schemata used to process emotional information [4]. The main idea therefore is that it is related to emotional processing difficulties, and the specific difficulty in finding appropriate words to describe feelings [5].

Recent thinking about alexithymia suggests challenges in the identification and description of emotions and is associated to difficulties in emotional self-regulation [6] and awareness of emotions [7]. These types of impairments are clearly related to deficits in mentalizing. The ability to mentalize can be considered as a type of social cognition that infers the ability to perceive and interpret human interaction and behaviour in forms of possible intentional mental states $[8,9]$. The current thinking about mentalizing is that is a multidimensional concept, there are 4 dimensions (each couple is organized on opposing polarities) which includes the following: self-other, cognitive-affective, internal-external, and automatic-controlled. Alexithymia (indicted limitation in emotion expression and identifying) may be referred to limits amongst the self, cognitive-affective, internal, and controlled features of mentalizing $[8,9]$, but this is not within the scope of this article.

One theoretical point needs to be addressed in advance here, that is if alexithymia is a psychological feature part of the personality as it is developed, or it is an acquired psychological abnormality having resulted from an adverse or trauma-like experience. The latter suggests psychodynamic interpretation, whilst it is possible that 1 develops alexithymia as a coping technique with stress. It has been suggested that alexithymia can be part of developmental character and therefore, permanent [5].

Alexithymia has been related in the second part of the last century to psychosomatic problems as well as psychological abnormalities. Alexithymia, for instance, is directly related to the degree of disorders of eating $[10,11]$. Alexithymia research on eating disorders populations was carried out [10-13] demonstrated difficulty in expressing emotions and the ability to differentiate between

Alexithymia, Body Image, and Eating

Problems in Saudi Arabian Females emotions as an essential deficit in eating disorder patients [14]. Patients with binge eating disorder have also shown inability to successfully regulate emotions [15]. Research showed that alexithymia could be related to severity of eating disorder symptoms $[10,11]$, and linked alexithymia and body dissatisfaction [16]. Another study supported the link, which it found those high in body dissatisfaction to have limitations recognizing their anger which a feature is related to alexithymia.

Most studies examined alexithymia in white Caucasians, but others approached different cultures too. For example, Newman found African-American experience less body satisfaction amongst college students, and less pressure on being thin, but they were like Caucasians to have challenges in identifying and expressing their emotions and distinguishing emotion from somatic symptoms [16].

Research is very sparse on alexithymia in the Arabic culture. There have been a couple of small studies in different contexts though addressing alexithymia. Al-Eithan for instance, examined alexithymia and mood disorders amongst mothers with disabled children [17]. It was found that those Arabic mothers have more alexithymia and mood problems compared with mothers of healthy children.

\section{Body Image}

People have a variety of perceptions about themselves, which differ according to which part they are looking at, either the physical, personal, or mental part of themselves. Body image is one of the perceptions people hold about themselves. In addition, body image is a multidimensional construct in which it holds 2 experiences about a person's body, subjective perceptual and attitudinal, mainly the physical appearance [18].

Body image as a perspective about the self has been studied using different concepts such as, body image disturbances, body image concerns, or body image quality of life. Research has shown much old and recent interest in body image amongst women as well as men. It showed that body dissatisfaction to be common in women and has been viewed as "normative discontent" [19]. Women desire to look smaller than their actual body size research suggested. Monteath and McCabe [20], for example, found that in women college students, about two-fifths of the women reported moderate to strong negative feelings about both individual body parts and their bodies. Body dissatisfaction evidently highly common, which indicates 
that female body image, is an important aspect for continued research, especially if it is related to health behaviours.

Cash et al. [21] proposed that body image abnormality is considered as a continuum of a person's body image dissatisfaction, as well as distress. Body image dissatisfaction extends to include hair, muscle tone, or any of numerous, not restricted to weight and body shape alone. Body image is a significant psychological concern, and it has much relation to eating disorders.

Research has supported the notion that body image is related to many psychological disorders. When women have dissatisfaction with body image, this would be associated with or a strong indicator of limited self-esteem [22], poor body image and low mood [23], social anxiety [24], and sexual deficits [25].

Furthermore, negative body image is related to a number of health behaviours and disorders; it was found to be related to excessive exercise, eating disorders, and problems with giving up smoking [26]. Other research showed that body image problems are strongly related to dietary restraint, and in turn connected to eating disorders [22]. On the other hand, improved health behaviour is related to improved body image. Studies on breast cancer patients showed that body image coping, women feeling positive about their bodies tend to also have stronger confidence in dealing with illness and showed more positive coping skills [27].

Thus, body image is a particularly important psychological feature that needs to be examined in women (and men) further to the scope of this study. It covers many aspects of the body-nevertheless it can be viewed a "constant" related to women's health, both psychologically and physically. It is related to self-esteem, mood, and illness. Positive body image, on the other hand, is also suggested it can provide better health-psychological and physical as well as better coping ability.

From the above research findings, it can be suggested that dissatisfied body image is a psychological burden female suffer from, and current cultural changes in Saud Arabia (as well as globalisation at large) makes it applicable to our local populations. But it also has been shown above that alexithymia may be part of the psychological problems amongst women who have eating problems or body image. Alexithymia is a strong current psychological construct address important aspect of emotion. In this disorder, people have significant problem in dealing, recognizing, processing, and expressing emotion.

We set out to conduct a number of small studies on a local population of females, starting with university stu-
Table 1. Demographic data of all participants

\begin{tabular}{lccc}
\hline & Mean & SD & Range \\
\hline Age & 21.38 & 1.35 & $19-29 \mathrm{yr}$ \\
Univ. Level & 6.34 & 4.45 & $1-8$ \\
GPA & $4.49 / 5$ & 2.27 & $3.0-4.97 / 5$ \\
BMI & 23.02 & 4.69 & $14.2-39.5$ \\
\hline
\end{tabular}

dents for they represent good age for such studies (regarding body image particularly) as well as convenience. Here, we report the first study. We wanted to see in this exploratory small study how present is both the Alexithymia disorder and poor body image. In addition, we wanted to see if both are related in presentation and further and if both have correlation with mood problems. We hypothesised that female university student in our sample (in a university in western Saudi Arabia) have dissatisfaction with body image and have higher than expected alexithymia.

The current study aimed therefore to examine the relationship between alexithymia and body image amongst Saudi females at a local university. We are not aware of any study in Arabic world that addressed this relationship. It seems certainly no Saudi Arabia or Gulf region study has been conducted on this subject either.

\section{Methods}

\section{Subjects}

This is a convenient sample consisted of (152) female students attending the university in West Saudi Arabia, after excluding 10 subjects (for incomplete participations, age above 30, etc.). They were all included but all free from drug abuse, or major psychological problems. All subjects were freely invited with their full consent to take part in a study on women and body image and emotional problems. They are rewarded for minor credits at the course work too. They were required not to put names or any identity identifier for anonymity. All participants are Saudi Arabia females as there is no other ethnic groups study at the university, that is, there is no ethnic subgroups.

Subject's mean age is (21.38 years) and SD (1.3 years); the majority are single (138) $90.8 \%$. The average level of university studies is (6.3 level) and SD 4.4. Their reported GPA is (4.49/5) whilst SD is $(2.27)$.

\section{Measures}

All subjects responded to basic demographic data, presented at Table 1.

Toronto Alexithymia Scale (Arabic Version)

This scale we applied to measure alexithymia [28]. The 20-item mainly measure 3 facets (1) challenges in identifying emotions and 
Table 2. Shows person correlations between TAS-20 Arabic, PTI-AS Arabic, BICS, and BSD scales

\begin{tabular}{|c|c|c|c|c|c|c|}
\hline & TAS-20 Arabic & PTI-AS Arabic & BICS & BSD now (a) & BSD desired (b) & BSD (a-b) difference \\
\hline TAS-20 Arabic & 1 & & & & & \\
\hline BICS & $\begin{array}{l}r=0.185^{*} \\
p=0.021\end{array}$ & $\begin{array}{l}r=0.167^{*} \\
p=0.04\end{array}$ & 1 & & & \\
\hline BSD desired (b) & $\begin{array}{l}r=-0.071 \\
p=0.389\end{array}$ & $\begin{array}{l}r=-0.101 \\
p=0.216\end{array}$ & $\begin{array}{l}r=0.142 \\
p=0.081\end{array}$ & $\begin{array}{l}r=0.330^{* *} \\
p=0.000\end{array}$ & 1 & \\
\hline BSD (a-b) difference & $\begin{array}{l}r=0042 \\
p=0.611\end{array}$ & $\begin{array}{l}r=0.145 \\
p=0.076\end{array}$ & $\begin{array}{l}r=0.264^{* *} \\
p=0.001\end{array}$ & $\begin{array}{l}r=0.805^{* *} \\
p=0.000\end{array}$ & $\begin{array}{l}r=0.339^{* *} \\
p=0.0000\end{array}$ & 1 \\
\hline
\end{tabular}

(2-tale significance: $\left.{ }^{*} p=0.05,{ }^{* *} p=0.01\right)$. BSD, body shape dissatisfaction; BICS, body image concern scale.

distinguishing them from physical sensations (2) limitation in emotion description, and 3) externally oriented thinking. These features are consistent with theoretical alexithymia construct. The scale uses a 5-point Likert scale ranging from 1 ("strongly disagree") to 5 ("strongly agree"). When the scores are equal to or greater than 61 this indicates the possible presence of alexithymia [29]. The Toronto Alexithymia Scale (TAS) has good internal consistency (Cronbach's alpha $=0.81$ ) and test-retest reliability $(0.77)$. Adequate convergent and concurrent validity has also been established [29]. Statistically has been shown to have acceptable reliability and validity in clinical [30] and non-clinical populations [31]. Furthermore, the TAS scale has also been, as stated above, used in a study in Saud Arabia on women [17].

\section{Psychological Treatment Inventory-Alexithymia Scale}

The Psychological Treatment Inventory-Alexithymia Scale (PTI-AS), a new, brief, measure of alexithymia consisting of 5 items [32]. This test has shown good validity and reliability on community sample; furthermore, it showed very good concurrent validity with the TAS-20. Correlations between the PTI-AS and the TAS-20 ( $r=0.74, p<0.001)$ are very significant. In addition, it was administered for patients with eating disorders; it showed very good discriminative validity compared to normal subjects [32]. It is very rare to see small scale with good statistical properties, strong valid scale such as (PTA Alex S), for a complex feature such as alexithymia. Given the fact that the scale is very simple, with very good statically power on a single factor [32], it was a good validating tool with the TAS-20 Arabic.

It was thought that it will add very good statistical value as well as information about the TAs-20 on this sample. It underwent the normal translation and back-translation. We found it very simple for subjects to answer, too. Results showed that there is significant correlation between (TAS-20 Arabic) and (PTI AlexS) $(r=0.44 ; p$ 0.000 ). These results support the validity of the TAS-20 Arabic for this population.

Alexithymia, Body Image, and Eating

Problems in Saudi Arabian Females
Body Shape Dissatisfaction (Visual Stunkard Figure Scale)

The Stunkard visual figure rating scale (body shape dissatisfaction [BSD]) was originally developed in 1983 [33], and later was used for a number of studies on body shape $[34,35]$. BSD test consists of a gender-specific scale that contains 9 schematic figures ranging from an underweight silhouette $(n=1)$ to an extremely obese silhouette $(n=9)$. Furthermore, the subjects were asked to indicate the ideal weight, and to select the actual body silhouette (current shape) and the silhouettes that they perceived as ideal (ideal shape), most attractive, and closest to their current body silhouette. The absolute value of BSD was derived from the discrepancies between the chosen current and ideal figures, regardless of direction of thinness or fatness preference. This figure rating scale has been showing good validity and was also found to have good test-retest reliability. Studies mentioned above have utilized the scale for both men and women, but we have only included the female part of the scale. Most of our sample was towards thinness as might be expected of females.

\section{Body Image Concern Scale}

Recent research has shown that body image concern has certain component that applied to people with body image. We have applied the newly developed body image concern scale, given its relevant to our hypothesized notion that our subject in their cultural context will show more concern regarding their appearance in social settings.

He et al. [36] developed the body image concern scale on university students in exploratory and explanatory analyses. They found it to have 6 factors: social avoidance, appearance dissatisfaction, preoccupation with reassurance, perceived distress/discrimination, defect hiding, and embarrassment in public, with good reliability and validity. Further, they found gender-specific pattern for women, which is relevant to our current study. We are not aware of any Arabic study that utilized such scale or this particular scale. It went again the usual translation and back-translation procedures, and it was very good for our sample. 
Table 3. Regression model

\begin{tabular}{llll}
\hline Variables entered/removed $^{\mathrm{a}}$ & \\
\hline $\begin{array}{l}\text { model } \\
\text { entered }\end{array}$ & $\begin{array}{l}\text { variables } \\
\text { removed }\end{array}$ & method \\
\hline 1 & & Stepwise (criteria: probability-of-F-to-enter $\leq 0.050$, probability-of-F-to-remove $\geq 0.100)$ \\
\hline
\end{tabular}

BICS, body image concern scale. ${ }^{\text {a }}$ Dependent variable: TAS-20 Arabic.

Table 4. Regression model

\begin{tabular}{|c|c|c|c|c|}
\hline \multicolumn{5}{|c|}{ Model summary } \\
\hline model & $\mathrm{R}$ & R square & $\begin{array}{l}\text { adjusted } \\
\mathrm{R} \text { square }\end{array}$ & $\begin{array}{l}\text { std. error of } \\
\text { the estimate }\end{array}$ \\
\hline 1 & $0.186^{\mathrm{a}}$ & 0.035 & 0.028 & 11.82413 \\
\hline
\end{tabular}

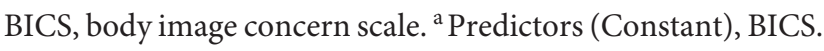

The scale consisted of 24 items; the subjects had to answer on a 5 -licker. We are here interested in the total max score (120) on the scale.

\section{Statistical Analysis}

Basic analysis of the demographic data is carried out. Then Person's correlation applied to examine the relationship between variables. This followed by basic regression analysis to see if 1 variable can be predicted by other variables.

\section{Results}

Basic data analysis and correlations were conducted using the SPSS 20. The regression analysis was conducted to examine the relationship between the variables. All data are presented in the following tables and texts.

(A) Basic demographic data are presented in Table 1: university levels are consistent of 8 total levels, 4 years for BA degree studies.

We noticed here that the GPA is rather raised which may reflect a university grading system or something else that is not relevant to our study at all. But we can suggest that we cannot expect much relationship to other variables given such mild skewed average.

(B) Psychological variables: the correlational study of certain variables is shown in Table 2.

When we examined the correlation between TAS-20 Arabic and other demographic data (age, BMI, and GPA), there was no significant correlations $(r=-0.134 ;-0.002$; and $r=0.058)$, respectively. This is interesting in that it tells us that demographic data are not related to our psychological variables at all. But psychological variable is possibly correlated to each other.

Further, regression analysis stepwise was applied to demonstrate which variable predict better the alexithymia in this sample. Results showed that BI scale has predicted only (3.5\%) of the variance as shown in Tables 3-5.

Hence, there is a relationship between alexithymia and body image as assessed by our scales here. What subjects think about their aimed or desired weight is not associated with their alexithymia neither their current weights. A very interesting observation because though their thinking about weight is related to body image, but obviously is not related to alexithymia. It explains that psychological factor (their emotional concern about body shape) is a factor in their emotion processing and difficulties (alexithymia).

\section{Discussion}

The objective of the current study is to explore the presence of alexithymia and its relationship to body image amongst female university students in Saudi Arabia. We are not aware of similar study here or in Arabic populations. The study is a part of few studies dealing with body image, eating problems and emotional difficulties. Here, we report the first part only.

The study showed that the sample has significant alexithymia features assessed by the TAS-20 Arab scale. These are interesting data, and it warrants further work and needs some comparative studies. Our finding is consistent with other research results $[10,11,37]$.

Further, the study has shown for the first time that body image assessed by 2 scales here is related significantly to the experience of alexithymia. We propose that alexithymia an (emotion neglect) psychological feature has negative experience that may be reflective of poor 
Table 5. Regression model

\begin{tabular}{llllll}
\hline Excluded variables $^{\mathrm{b}}$ & \multicolumn{6}{l}{} \\
\hline model & beta in & $T$ & sig. & $\begin{array}{l}\text { partial } \\
\text { correlation }\end{array}$ & $\begin{array}{l}\text { collinearity } \\
\text { statistics } \\
\text { tolerance }\end{array}$ \\
\hline 1 & & & & & \\
BMI & & & & & \\
BSD now & $-0.073^{\mathrm{a}}$ & -0.858 & 0.392 & -0.070 & 0.887 \\
BSD desired & $-0.099^{\mathrm{a}}$ & -1.022 & 0.309 & -0.083 & 0.885 \\
BSD difference & $-0.008^{\mathrm{a}}$ & -0.098 & 0.922 & -0.008 & 0.980 \\
Age & $-0.119^{\mathrm{a}}$ & -1.488 & 0.139 & -0.121 & 0.930 \\
\hline
\end{tabular}

BSD, body shape dissatisfaction; BICS, body image concern scale. ${ }^{\text {a }}$ Predictors in the model (Constant), BICS. ${ }^{\mathrm{b}}$ Dependent variable: TAS-20 Arabic.

body image in our sample. It is possible that the resulted abnormality is part of a psychological phenomenon bigger than the 2 variables addressed here; this needs further work.

As indicated in the introduction that the concept of alexithymia is given more evidence that it can be developed in the individual in association with other psychological concerns without the expected trauma or abuse, as suggested initially. This study lends support to the idea of (acquisition-development) aspect of alexithymia free of trauma, or else how it can be explained that our normal non-clinical group showed such abnormality. But this is not the scope of current study, and it needs further validation.

This study is an exploratory 1 . The study's strengths lie in the fact it is new data using the scales mentioned above in this sample, with reasonable sample numbers. The study for first-time reports associations between alexithymia and body image here. The study helps us to understand further the psychological problems related to people with body image. It helps us to examine such problems on clinical population to understand better the abnormalities expected amongst people with eating problems, for instance.

Limitation of study however is related to the sample. The study has only university students - non-clinical sample. It also does not compare them with male or younger students. The study also will benefit from validation work on some of the scale used in the present study.

It will be very helpful if also the age span will be lowered to examine early experiences of the issues addressed here amongst teen females in Saudi Arabia. Further studies needed in both males and females.

\section{Acknowledgment}

Many thanks to Ms. Aisha Khan for her valuable language review.

\section{Statement of Ethics}

All participants provided verbal and written approval informed consent to participate in the study which was conducted in accordance with the Declaration of Helsinki. It was locally approved by (King Abdulaziz University, Psychology Department Ethical Committee; January 2018. February 10, 2018)."

\section{Conflict of Interest Statement}

There is no conflict of interest.

\section{Funding Sources}

The authors did not receive any funding source for this study.

\section{Author Contributions}

Dr. M.E. contributed to initial ideas/concepts of the study, plan, tests preparation, and data analyses, as well as writing up the paper. Dr. H.S. discusses the study plan, full data collection, references, and writing review. Miss I.E. contributed to data analyses.

\section{Data Availability Statement}

Due to technical and repository reasons, the data are available only upon request and by writing from the correspondence author. 


\section{References}

1 Taylor GJ, Parker JD, Bagby RM, Bourke MP. Relationships between alexithymia and psychological characteristics associated with eating disorders. J Psychosom Res. 1996 Dec 1; 41(6):561-8.

2 Zlotnick C, Mattia JI, Zimmerman M. The relationship between posttraumatic stress disorder, childhood trauma and alexithymia in an outpatient sample. J Traum Stress. 2001 Jan 1;14(1):177-88.

3 de Groot JM, Rodin G, Olmsted MP. Alexithymia, depression, and treatment outcome in bulimia nervosa. Compr Psychiatry. 1995 Jan;36(1):53-60.

4 Primmer J Understanding the dimensional nature of alexithymia. J Conscious Stud. 2007; 20(21):111-31.

5 Graeme J, Taylora R, Michael B, James DA. What's in the name "alexithymia"? A commentary on "affective agnosia: expansion of the alexithymia construct and a new opportunity to integrate and extend Freud's legacy". Neurosci Biobehav Rev. 2016;68:1006-20.

6 Larsen JK, Brand N, Bermond B, Hijman R. Cognitive and emotional characteristics of alexithymia: a review of neurobiological studies. J Psychosom Res. 2003 Jun 1;54(6):53341.

7 Luyten P, Van Houdenhove B, Lemma A, Target M, Fonagy P. Vulnerability for functional somatic disorders: a contemporary psychodynamic approach. J Psychother Integr. 2012 Sep;23(3):250

8 Luyten P, Fonagy P, Lowyck B, Vermote R. Assessment of mentalization. . In: Bateman AW, Fonagy PE, editors. Handbook of mentalizing in mental health practice: American Psychiatric Publishing, Inc.; 2012

9 Luyten P, Fonagy P. The neurobiology of mentalizing. Personality Disord. 2015 Oct; 6(4):366.

10 Bydlowski S, Corcos M, Jeammet P, Paterniti S, Berthoz S, Laurier C, et al. Emotion-processing deficits in eating disorders. Int J Eat Disord. 2005 May;37(4):321-9.

11 Carano A, De Berardis D, Gambi F, Di Paolo C, Campanella D, Pelusi L, et al. Alexithymia and body image in adult outpatients with binge eating disorder. Int J Eat Disord. 2006 May;39(4):332-40.

12 De Berardis D, Campanella D, Gambi F, La Rovere R, Sepede G, Core L, et al. Alexithymia, fear of bodily sensations, and somatosensory amplification in young outpatients with panic disorder. Psychosomatics. 2007 May 1;48(3):239-46.
13 Heatherton TF, Baumeister RF. Binge eating as escape from self-awareness. Psychol Bull. 1991 Jul;110(1):86.

14 Bruch H. Perceptual and conceptual disturbances in anorexia nervosa. Psychosom Med. 1962 Mar 1;24(2):187-94.

15 Wheeler K, Greiner P, Boulton M. Exploring alexithymia, depression, and binge eating in self-reported eating disorders in women. Perspect Psychiatr Care. 2005 Jul;41(3):114-23.

16 Newman LM. The role of alexithymia in ethnic groups on eating-related attitudes and behaviours. Doctor of Psychology (PsyD), dissertation, Psychology, Old Dominion University; 2003;64(11-B):5795.

17 Al-Eithan $\mathrm{MH}$, Al Juban HA, Robert AA. Alexithymia among Arab mothers of disabled children and its correlation with mood disorders. Saudi Med J. 2012 Sep 1;33(9):995-1000.

18 Cash TF, Pruzinsky T. Body image: a handbook of theory, research, and clinical practice: The Guilford Press; 2002 Jan 13.

19 Rodin J, Silberstein L, Striegel-Moore R. Women and weight: a normative discontent. Nebraska symposium on motivation: University of Nebraska Press; 1985.

20 Monteath SA, McCabe MP. The influence of societal factors on female body image. J Soc Psychol. 1997 Dec 1;137(6):708-27.

21 Cash TF, Phillips KA, Santos MT, Hrabosky JI. Measuring "negative body image": validation of the body image disturbance questionnaire in a nonclinical population. Body Image. 2005 Dec 1;1(4):363-72.

22 Johnson F, Wardle J. Body dissatisfaction, and psychological distress: a prospective analysis. J Abnorm Psychol. 2005;114(1):119-25.

23 Noles SW, Cash TF, Winstead BA. Body image, physical attractiveness, and depression. J Consult Clin Psychol. 1985 Feb;53(1):88.

24 Cash TF, Fleming EC, Alindogan J, Steadman L, Whitehead A. Beyond body image as a trait: the development and validation of the body image states scale. Eat Disord. 2002 Jun 1; 10(2):103-13.

25 Wiederman MW. Body image and sexual functioning. In: Cash TF, Pruzinsky T, editors. Body image: a handbook of theory, research, and clinical practice 2002. New York: Guilford. p. 287-94.

26 King TK, Matacin M, White KS, Marcus BH. A prospective examination of body image and smoking cessation in women. Body Image. 2005 Mar 1;2(1):19-28.
27 Pikler V, Winterowd C. Racial and body image differences in coping for women diagnosed with breast cancer. Health Psychol. 2003 Nov;22(6):632.

28 Taylor GJ, Ryan D, Bagby RM. Toward the development of a new self-report alexithymia scale. Psychother Psychosom. 1985;44(4): 191-9.

29 Bagby RM, Parker JD, Taylor GJ. The twentyitem Toronto alexithymia scale - I. item selection and cross-validation of the factor structure. J Abnorm Psychol. 1994 Jan 1;38(1):2332.

30 Troop NA, Schmidt UH, Treasure JL. Feelings and fantasy in eating disorders: a factor analysis of the Toronto alexithymia scale. Int J Eat Disord. 1995 Sep;18(2):151-7.

31 Swift L, Stephenson R, Royce J. The 20 item Toronto alexithymia scale: validation of factor solutions using confirmatory factor analysis on physiotherapy out patients. Psychol Psychother. 2006 Mar;79(1):83-8.

32 Stunkard AJ, Sorensen T, Schulsinger F. Use of the Danish adoption register for the study of obesity and thinness S. In: Kety, editor. The genetics of neurological and psychiatric disorders. New York, NY: Raven Press; 1983. p. $115-20$

33 Gori A, Giannini M, Palmieri G, Salvini R, Schuldberg D. Assessment of alexithymia: pychometric properties of the psychological treatment inventory-alexithymia scale (PTIAS). Psychology. 2012;3(3):231.

34 Cheung YT, Lee AM, Ho SY, Li ET, Lam TH, Fan SY, et al. Who wants a slimmer body? The relationship between body weight status, education level and body shape dissatisfaction among young adults in Hong Kong. BMC Public Health. 2011 Dec 1;11(1):835.

35 Prasad V, Kanimozhy K, Venkatachalam J, Madhanraj K, Singh Z. Body shape dissatisfaction and overweight noesis among polytechnic college students in Puducherry-A cross sectional study. Int J Indian Psychol. 2015;2:44-52.

36 He W, Zheng Q, Ji Y, Shen C, Zhu Q, Wang W. Development of a body image concern scale using both exploratory and confirmatory factor analyses in Chinese university students. Neuropsychiatr Dis Treat. 2017;13: 1419.

37 Sylvie B, Fabienne P, Nathalie G, Maurice C, Mark GH. Observer-and self-rated alexithymia in eating disorder patients: levels and correspondence among three measures. J Psychosom Res. 2017 Mar 1;62(3):341-7. 